\title{
Heterogeneity in the inter-tumor transcriptome of high risk prostate cancer
}

\author{
Alexander W Wyatt ${ }^{1 \dagger}$, Fan Mo ${ }^{1 \dagger}$, Kendric Wang ${ }^{1}$, Brian McConeghy ${ }^{1}$, Sonal Brahmbhatt ${ }^{1}$, Lina Jong ${ }^{1}$, \\ Devon M Mitchell', Rebecca L Johnston ${ }^{1}$, Anne Haegert ${ }^{1}$, Estelle Li ${ }^{1}$, Janet Liew ${ }^{1}$, Jake Yeung ${ }^{1}$, Raunak Shrestha',

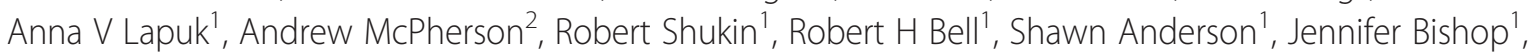 \\ Antonio Hurtado-Coll ${ }^{1}$, Hong Xiao ${ }^{3}$, Arul M Chinnaiyan ${ }^{3}$, Rohit Mehra ${ }^{3}$, Dong Lin ${ }^{1,4}$, Yuzhuo Wang ${ }^{1,4}$, Ladan Fazli ${ }^{1}$, \\ Martin E Gleave ${ }^{1}$, Stanislav V Volik ${ }^{1}$ and Colin C Collins ${ }^{1 *}$
}

\begin{abstract}
Background: Genomic analyses of hundreds of prostate tumors have defined a diverse landscape of mutations and genome rearrangements, but the transcriptomic effect of this complexity is less well understood, particularly at the individual tumor level. We selected a cohort of 25 high-risk prostate tumors, representing the lethal phenotype, and applied deep RNA-sequencing and matched whole genome sequencing, followed by detailed molecular characterization.

Results: Ten tumors were exposed to neo-adjuvant hormone therapy and expressed marked evidence of therapy response in all except one extreme case, which demonstrated early resistance via apparent neuroendocrine transdifferentiation. We observe high inter-tumor heterogeneity, including unique sets of outlier transcripts in each tumor. Interestingly, outlier expression converged on druggable cellular pathways associated with cell cycle progression, translational control or immune regulation, suggesting distinct contemporary pathway affinity and a mechanism of tumor stratification. We characterize hundreds of novel fusion transcripts, including a high frequency of ETS fusions associated with complex genome rearrangements and the disruption of tumor suppressors. Remarkably, several tumors express unique but potentially-oncogenic non-ETS fusions, which may contribute to the phenotype of individual tumors, and have significance for disease progression. Finally, one ETS-negative tumor has a striking tandem duplication genotype which appears to be highly aggressive and present at low recurrence in ETS-negative prostate cancer, suggestive of a novel molecular subtype.

Conclusions: The multitude of rare genomic and transcriptomic events detected in a high-risk tumor cohort offer novel opportunities for personalized oncology and their convergence on key pathways and functions has broad implications for precision medicine.
\end{abstract}

\section{Background}

In recent years the application of next-generation sequencing to hundreds of prostate tumors has defined novel molecular subtypes and characterized extensive genomic aberration underlying disease initiation and progression [1,2]. Rearrangements of ETS transcription factors define approximately $50 \%$ of tumors [3], while mutations in the E3 ubiquitin ligase adapter SPOP and/or disruption to

\footnotetext{
*Correspondence: ccollins@prostatecentre.com

${ }^{\dagger}$ Equal contributors

${ }^{1}$ Vancouver Prostate Centre \& Department of Urologic Sciences, University of British Columbia, 2660 Oak Street, Vancouver, BC V6H 3Z6, Canada Full list of author information is available at the end of the article
}

CHD1, a chromatin remodeling factor, have been reported in approximately $20 \%$ of tumors [4-6]. Both ETS rearrangements and $S P O P$ mutations appear to be early events in prostate cancer development and proceed to influence the nature of future aberration, resulting in subtypespecific patterns of downstream genome rearrangement [6]. However, the glut of genomic and epigenomic aberrations accrued during progression continue to converge on characteristic 'prostate cancer pathways' with scant regard to molecular subtype: ultimately leading to a highly heterogeneous transcriptomic landscape, centered on an overactive androgen receptor (AR) signaling axis. This heterogeneity 
confounds attempts to advance beyond clinically-based nomograms for patient prognostication and to accurately stratify tumors for precision medicine. Furthermore, since driver mechanisms within individual prostate tumors are highly diverse (as evidenced by lack of highly recurrent mutations), specific events are in many tumors likely to be unique.

High-risk clinically localized prostate cancer, a potentially lethal disease, is diagnosed in up to one-quarter of patients [7], and tends to be highly rearranged at the genomic level, harboring multiple drivers [8]. Since previous sequence-based studies have focused predominantly on the genome or exome, we hypothesized that detailed transcriptome dissection of high-risk prostate tumors will reveal unique and contemporary driver aberration. In this study we characterized the transcriptomes of 25 high-risk primary prostate tumors including 10 neoadjuvant treated tumors, identifying novel gene expression signatures and hundreds of fusion transcripts, some of which may be therapeutically tractable. Although highly heterogeneous, aberration converged on distinct cancer pathways and functions, with impact for future efforts to stratify patients for precision medicine. Finally we identified a previously unrecognized tandem duplicator genotype in ETS-rearrangement negative prostate cancer.

\section{Results}

\section{Evidence of therapy response and resistance in neo- adjuvant treated tumors}

We performed deep transcriptome sequencing (median $711 \times$ coverage), shallow whole genome sequencing (median $23 \times$ coverage), and aCGH copy number profiling on 25 high-risk primary prostate tumors, five matched adjacentbenign prostate tissues, and a patient-derived xenograft (PDX) originating from a needle biopsy of high-risk primary disease (Figure 1A; Additional file 1: Tables S1-3). Detailed follow-up information for more than 2 years was present for all but two patients: the majority of patients $(20 / 25)$ had a PSA recurrence or never reached PSA nadir, and eight of these have so far progressed with distant metastases, emphasizing the selected high-risk nature of the cohort.

Ten tumors were exposed to neo-adjuvant hormone therapy (NHT) for 1 to 9 months, and global transcript profiling demonstrated a marked split between these samples and the untreated (hormone-naïve) tumors (Figure 1B; Additional file 1: Table S4; Additional file 2: Figure S1). Significantly downregulated genes in NHT tumours (DESeq comparison; Benjamini-Hochberg $P<0.05$ ) were typically androgen responsive (for example, TMPRSS2, KLK3, $B M P R 1 B, T P D 52)$ or steroidogenesis-related (for example, DHCR24, SCD), consistent with a reduction in androgen receptor activity (Figure 1C; Additional file 1: Table S5; Additional file 3: Text S1). This effect is in stark contrast to the frequent observation of $A R$ reactivation in castration-resistant prostate cancer; which is often concomitant with the overexpression of de novo steroidogenic enzymes [9]. Upregulated genes in NHT tumors were linked to growth suppression and increased apoptosis (for example, DUSP2, DUSP4, CCDC8, TNS4) and also with cytotoxic $\mathrm{T}$ lymphocytes (for example, CD8A, $G Z M K)$, with the latter in line with previous reports demonstrating an increase in prostatic infiltration of lymphocytes post-hormone treatment $[10,11]$. However, although the data suggested that most tumors were responding to androgen deprivation therapy at the time of tumor collection, four tumors displayed elevated CHGA expression at the mRNA level (Figure 1D). CHGA is a marker of NEPC: an aggressive anaplastic subtype that is very rare at diagnosis but may emerge after long term androgen deprivation [12]. NEPC cells are AR-negative and are thought to arise via 'transdifferentiation' from AR-positive adenocarcinoma cells [13]. Elevated CHGA mRNA expression is of unclear significance in three of the four positive tumors since they exhibited $<10 \%$ CHGA positive cells by immunohistochemistry (Figure 1E-G). However, one tumor (T20) exhibited widespread CHGA positivity, and morphology distinctive of neuroendocrine prostate cancer (NEPC) (Figure 1H). Dual immunohistochemistry for AR and CHGA on the same patient's diagnostic biopsy (prior to NHT; diagnosis of adenocarcinoma, Gleason $4+5$ ) revealed that biopsy contained few CHGA positive cells, while the prostatectomy sample (after 8 months of goserelin and flutamide) harbored few AR positive foci (Figure 1H, Additional file 2: Figure S2). Although we cannot exclude biopsy sampling bias, FISH on the prostatectomy sample confirmed the presence of the androgen-driven TMPRSS2-ERG rearrangement, suggesting an adenocarcinoma origin for the NEPC component within tumor T20 and the potential that this therapy resistant tumor was driven (at least in part) by NHT treatment (Figure 1; Additional file 2: Figure S2; Additional file 3: Text S1) [14-17].

\section{Outlier gene expression suggests contemporary tumor- dependent pathway affinity}

Despite elucidation of distinct molecular subtypes, the transcriptomic diversity of adenocarcinoma at prostatectomy is high, due in part to the protracted natural history of tumor development and the varying temporal relevance of a range of rare driver events. Concordantly, we did not observe broad gene expression differences between all tumor and benign samples at the significance levels used for the NHT comparisons described above (DESeq comparison; Benjamini-Hochberg $P<0.05$ ) (Additional file 1 : Table S4). Nevertheless, the contemporary reliance (that is, at the time of sample collection) of individual tumors on particular cellular functions or signaling pathways for 


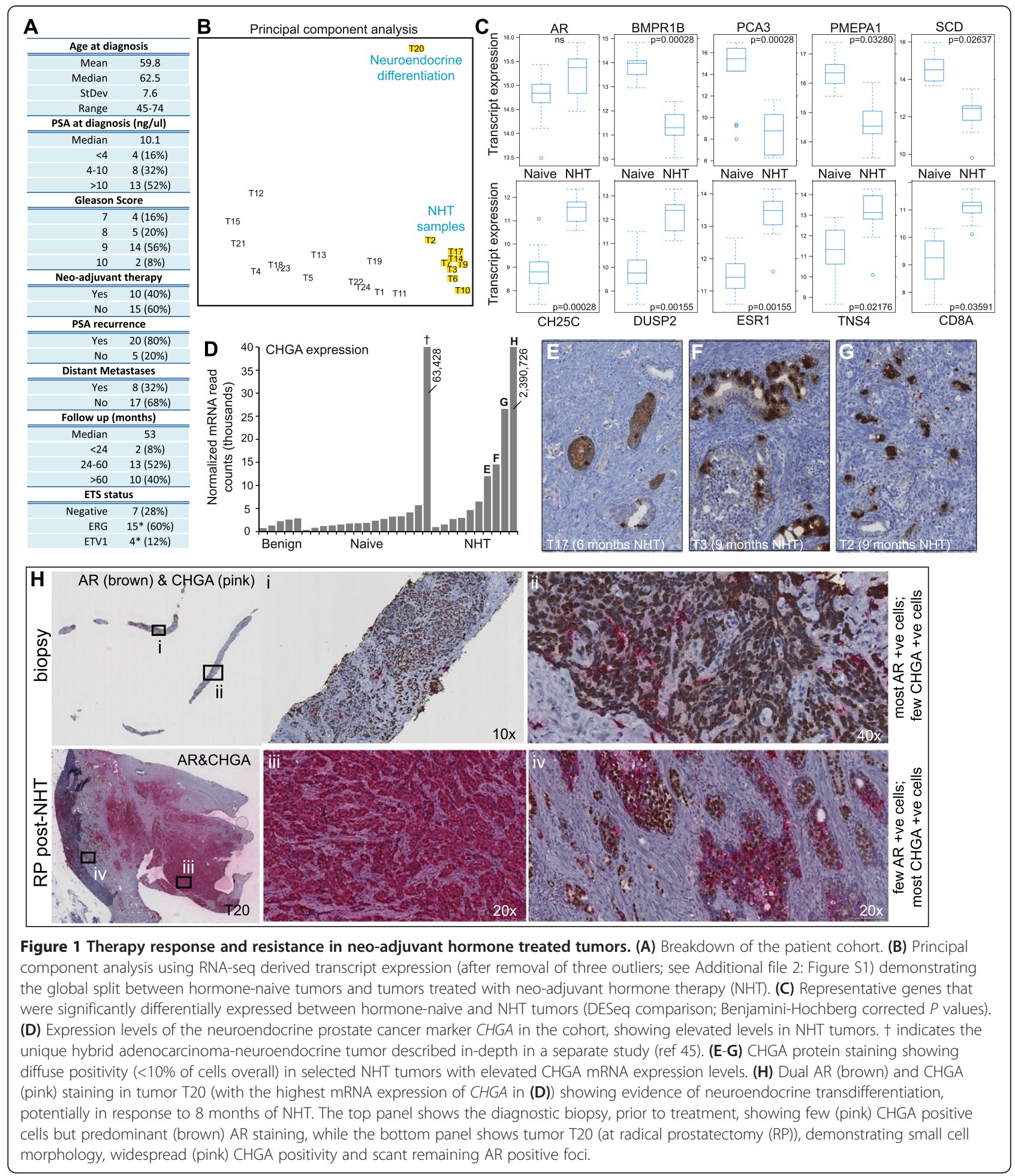

growth and survival should be overt at the transcriptome level. Therefore, to capture inter-tumor differences and similarities in pathway affinity, and to take advantage of the high dynamic range and absolute quantification inherent of RNA-seq data, we identified genes in each tumor that were expressed at an outlier level in that tumor and no more than one-third of the cohort (median outlier transcripts per sample $=437$; Additional file 1: Table S6). This 'recurrent' outlier analysis allowed the detection of individual-specific outliers, and those that are more frequent. Remarkably, the outlier genes of 17/25 tumors showed significant enrichment (Benjamini-Hochberg 
corrected $P<0.05)$ within at least one canonical pathway (Figure 2; Additional file 1: Tables S7 and S8).

Three main 'clusters' of pathway enrichment emerged (Figure 2). Pathways associated with cell cycle progression (for example, Mitotic Roles of Polo-Like Kinase) were significantly enriched in six samples, potentially indicating a subset of tumors with elevated proliferation rates: a claim further substantiated by high Ki67 indices in these tumors (Figure 2; Additional file 2: Figure S3). Enrichment was driven by the upregulation of several key regulators of the cell cycle, including PLK1, CDC25A, and $C D K 1$, genes known to be associated with aggressive tumors, and with inhibitors in various stages of clinical development [18-20]. The translational control pathway 'EIF2 Signaling' was enriched in four tumors, with threequarters also overexpressing genes involved in 'mTOR

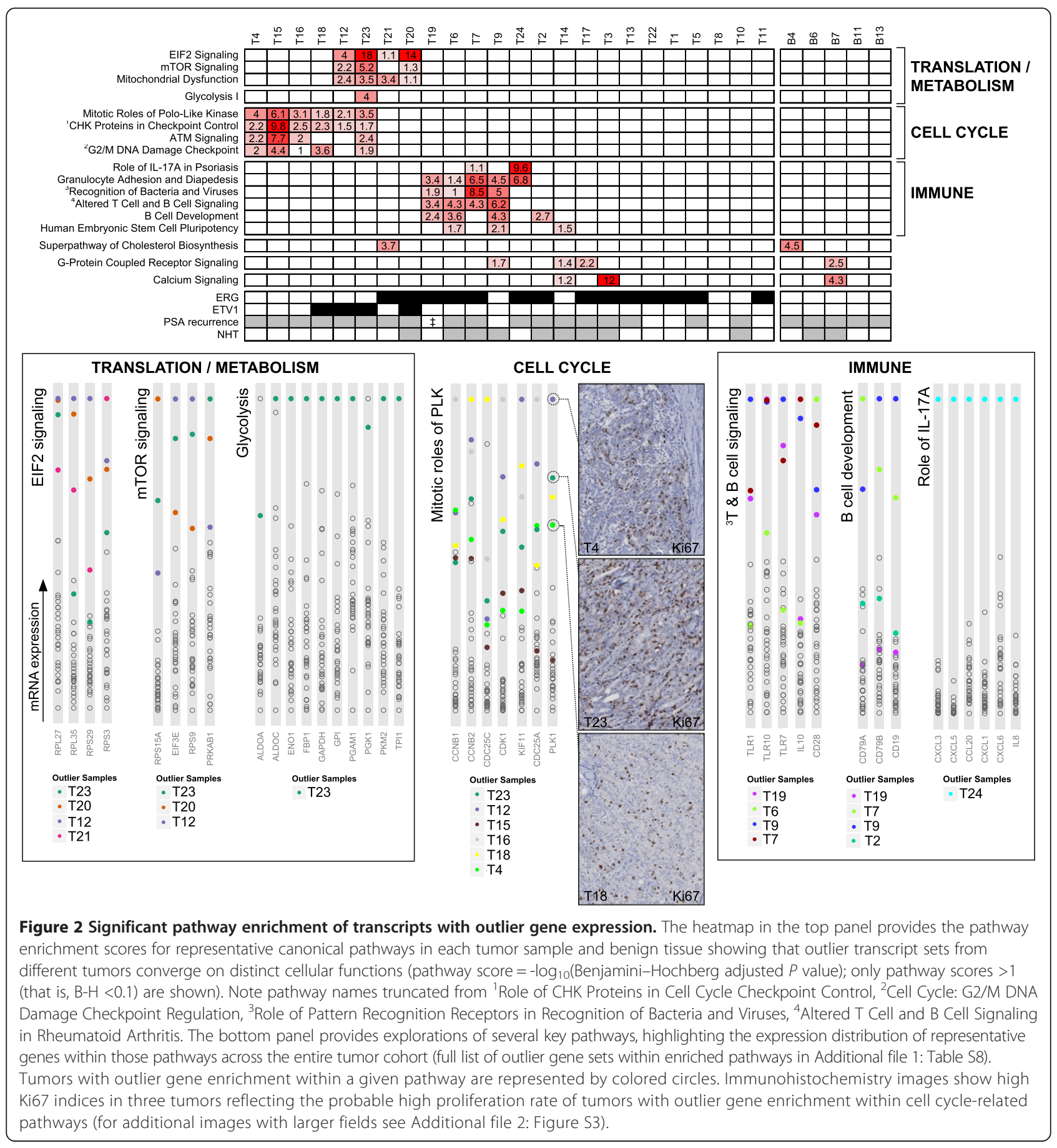


Signaling, a druggable pathway of considerable potential in prostate cancer [21]. This enrichment was caused in part by the upregulation of a range of ribosomal genes, a species frequently overexpressed in cancer [22]. Although increased ribosomal gene transcription may simply reflect a cell with higher proliferation, ribosomal biogenesis can itself be a driver of cell cycle progression, and several prominent oncogenes mediate their effects via the ribosome [22]. Interestingly, tumors with outlier gene enrichment in EIF2/mTOR also overexpressed genes related to mitochondrial dysfunction, and the tumor (T23) with the most significant enrichment in these three pathways had outlier expression of $A K T 1$ (notable since mitochondrial respiration defects can lead to the activation of AKTmediated survival [23]; Additional file 2: Figure S3). Furthermore, T23 also demonstrated striking enrichment in the 'Glycolysis I' pathway, including marked upregulation of the Warburg-effect facilitator PKM2 (evidence of coordinated regulation of this pathway was similarly evident in public data (Additional file 2: Figure S3)). Finally, a third group of tumors demonstrated enrichment of outlier gene expression within pathways associated with the immune system. Four of these tumors were exposed to NHT and distinct patches of infiltrating lymphocyte populations were evident by histology (Additional file 2: Figure S4). Accordingly, these samples had high expression of B cell markers (for example, CD79, CD19, BLK) and/or toll-like receptors (for example, TLR1), as well as $\mathrm{T}$ cell markers such as $C D 4, C D 8 A$, and $C D 3 A$. Nevertheless, two tumors within the 'immune group' were untreated (T19 and T24) and although T19 had high expression of $\mathrm{T}$ and $\mathrm{B}$ cell markers, T24 had scant evidence of a significant population of invading lymphocytes either by histology or mRNA expression of immune cell markers (Additional file 2: Figure S4). High, unique expression of chemokines including CXCL1, CXCL5, and IL8 in this tumor may therefore have tumor cell origins. Furthermore, it is worth noting that outlier genes from the five adjacent benign samples did not show enrichment in any of the three pathway clusters defined above, including benign samples matched to two tumors with high immune enrichment (Figure 2).

Since only two patients had died at time of writing, we evaluated instead the biochemical recurrence-free survival of different pathway groups. Despite the fact that the entire cohort was high-risk, the eight patients in the cell cycle and translation/metabolism groups fared significantly worse than all other patients $(P=0.0009$; log rank test) (Additional file 2: Figure S5). Overall, these data promise a strategy to classify tumors based on contemporary druggable pathway affinity, which if corroborated in larger RNA sequence cohorts in the future, has potential to compliment patient stratification for precision medicine and provide insight into the functional consequences of heterogeneity.
High frequency of ETS fusions, complex rearrangements, and disruption to tumor suppressors

DNA rearrangement is a hallmark of prostate cancer, causing distinctive chromosomal copy number alterations and creating oncogenic fusion genes [1]. Sentinel work over the past decade has defined the landscape of recurrent fusion genes in prostate cancer as limited to ETS gene rearrangements in approximately $50 \%$ of tumors, and rare (approximately $1 \%$ ) rearrangement to $R A F$ kinase family members [24]. However, non-recurrent events have attracted less attention, but may still have significant relevance within specific tumors. Indeed, genome breakpoints are likely to be an underestimated mutational mechanism in prostate cancer as they appear to be enriched within tumor suppressor genes, but analyses are complicated by the large number of passenger events (prostate tumors frequently harbor hundreds of genome rearrangements), and the false positives that are inevitable when predicting genomic events. Therefore, we focused our rearrangement analyses on our deep transcriptome data, since theoretically only genome breakpoints occurring within gene loci will be detectable and exon-exon junctions are less likely to cause mapping issues. We hypothesized that disrupted genes would tend to fall in prostate cancer-related pathways and that a fraction of non-recurrent fusion genes would have oncogenic potential.

Using an integrated approach involving the fusion gene prediction tool deFuse [25], gene expression profiles and genome copy number data we identified 242 fusion transcripts arising from genome rearrangement in the $25 \mathrm{pa}-$ tient tumors and the PDX tumor (validation of 75 novel fusion transcripts was performed by PCR and Sanger sequencing; validation rate $>95 \%$ [72/75]; Additional file 1: Table S9). Twenty-three out of 26 tumors expressed $\geq 1 \mathrm{fu}$ sion, at an average burden of 11 fusion transcripts. The majority $(18 / 26$; 69\%) were positive for an ETS gene rearrangement (15 ERG, 4 ETV1; Figure 3A; Additional file 2: Figure S6); and $E R G$ fusion junction read counts correlated with $E R G$ gene expression $(\mathrm{r}=0.82)$. Given the recent characterization of high frequency complex rearrangements (also termed 'chromoplexy') in prostate tumors [6], we searched for evidence that fusion genes were involved in complex rearrangements including $>2$ genome breakpoints. Despite shallower DNA sequence data, 210/242 fusions were evaluable (expressed in tumors with paired DNA sequence coverage $>5 \times$ ) for involvement in complex rearrangements, and we could identify DNA breakpoints for 169 (80\%; Additional file 1: Table S9). There were 37 separate complex rearrangements involving $83 / 210$ fusion transcripts (validation rate 100\% [13/13]; Figure 3A-F; Additional file 1: Table S10), with 16 tumors containing $\geq 1$ complex rearrangement. Of 17 evaluable ETS fusions, 14 were present in a complex rearrangement, and ETS rearrangements were involved in $38 \%(14 / 37)$ of 


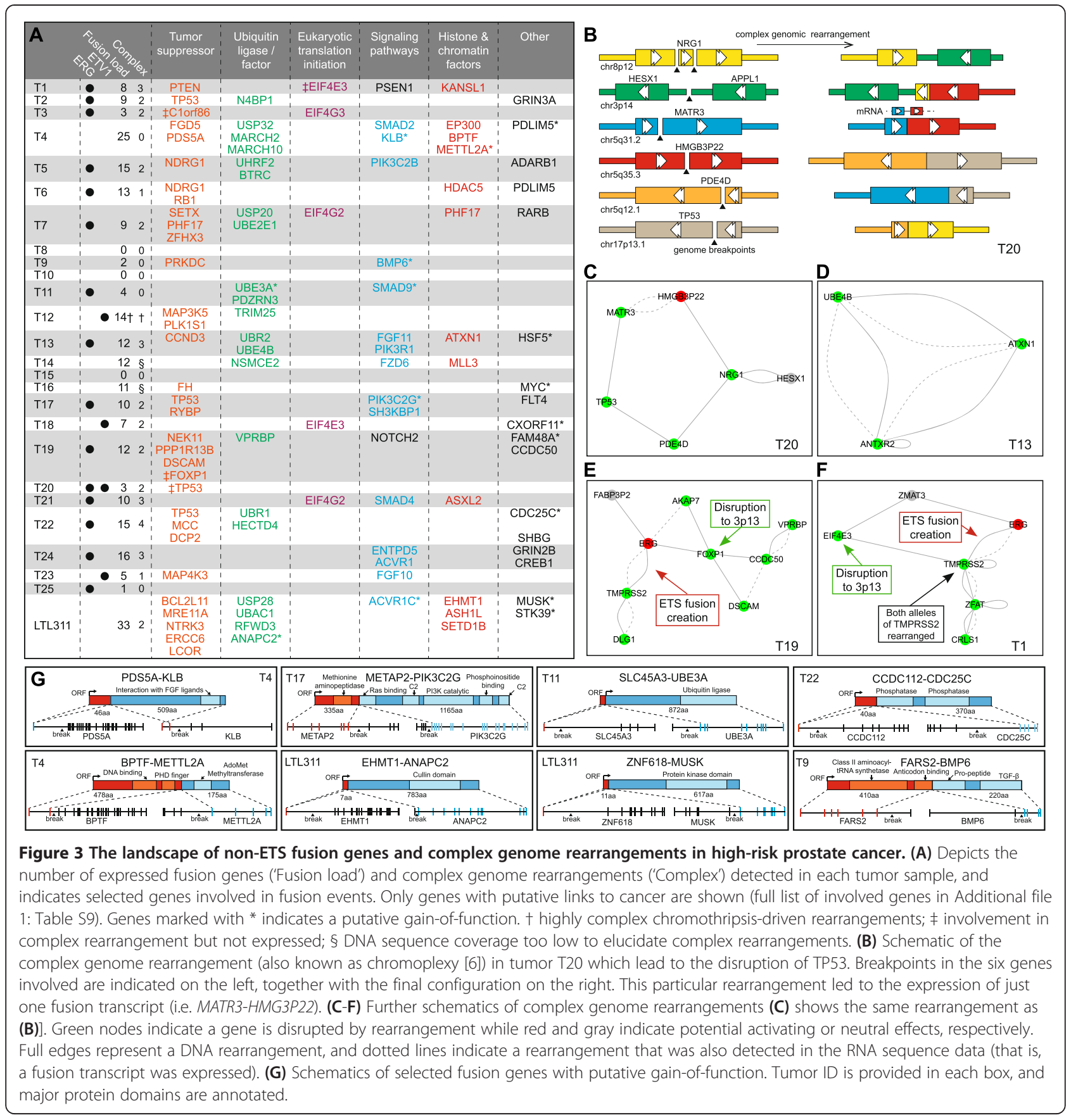

complex events. It is of note that the NHT tumor (T20) with a significant NEPC component was positive for both ERG and ETV1 rearrangements (by RNA sequencing and PCR validation); raising the possibility of multi-focal 'collision' cancers where only the ERG rearranged cells 'transdifferentiated' into NEPC (discussed further in Additional file 3: Text S1).

The majority of fusion genes were likely to result in loss-of-function of one or both partners through interruption and/or truncation of the coding sequence. In 18 tumors fusion gene events caused disruption to known or putative tumor suppressor genes, including genes associated with TP53 apoptosis (for example, TP53 in four tumors; PPP1R13B), MAPK p38 apoptosis (for example, $M A P 3 K 5)$, cell cycle progression (for example, $R B 1, C C N D 3$ ), DNA damage response (for example, MRE11A), and DNA architecture (for example, PDS5A) (Figure 3A; Additional file 1: Table S9). Indeed, using Ingenuity Pathway Analysis, the top canonical pathway enriched by the 344 unique fusion partners (that mapped to a protein 
coding gene) was the 'Molecular Mechanisms of Cancer' (Benjamini-Hochberg corrected $P=3.4 \times 10^{-5}$ ) and the top disease/bio function was 'Cancer: Solid Tumor' (Benjamini-Hochberg corrected $P=1.66 \times 10^{-10}$ ). Other classes of rearranged genes included E3 ubiquitin ligases and members of eukaryotic translation initiation complexes (Figure 3A). Particularly notable within the latter was disruption to EIF4E3, a gene residing within a genome rearrangement hotspot on chromosome 3p13 harboring three context-specific tumor suppressors FOXP1, RYBP, SHQ1 [8,26]. EIF4E3 falls in between FOXP1 and $R Y B P$, and is itself a purported tumor suppressor [27]. Although 3p13 is deleted in approximately $20 \%$ of prostate tumors, there is an enrichment of 3p13 deletions in $E R G$ positive tumors [26]. Our data suggest this association may be partly underpinned by complex genome rearrangement, since two tumors appeared to have disruption to 3p14 simultaneously to ERG rearrangement (complex rearrangements in tumor T1 (EIF4E3) and tumor T19 (FOXP1); Figure 3E and F).

\section{Expression of non-ETS in-frame fusion genes}

We searched for evidence of non-ETS fusions which could be oncogenic. Approximately 60 fusion genes were predicted to have an open reading frame across the fusion junction, while 45 were associated with outlier expression of the 3' gene (Additional file 1: Table S9). Several candidates had theoretical gain-of-function (Figure 3G; Additional file 1: Table S9; Additional file 2: Figure S6), including genes within intracellular signaling cascades (for example, WNT or PI3K pathways). For example, a $P D S 5 A-K L B$ fusion (tumor T4) led to 10 -fold overexpression of a truncated, but in-frame, $K L B$ transcript. KLB (beta-Klotho) is a tissue restricted single-pass transmembrane protein that acts a co-receptor for FGF family members and has been implicated in prostate cancer [28,29]. Expression of $K L B$ in T4 is driven by PDS5A, a known tumor suppressor involved in DNA repair and sister chromatid cohesion, disruption of which may also confer a selective benefit. METAP2-PIK3C2G in tumor T17 resulted in the seven-fold upregulation of in-frame PIK3C2G, while FARS2-BMP6 in tumor T9 may also be relevant since BMP6 is linked to invasion of prostate cancer cells [30]. The PDX LTL311 expressed a ZNF618MUSK fusion transcript resulting in the expression of a transcript coding for the protein kinase domain of MUSK, a muscle-specific receptor tyrosine kinase that is not normally expressed in prostate.

Genes involved in cell cycle regulation were also potentially activated, including in hormone-naïve tumor T22 where a fusion was associated with six-fold overexpression of tyrosine phosphatase CDC25C. In LTL311 the ubiquitously expressed EHMT1 likely drove overexpression of ANAPC2. ANAPC2 is a component of the anaphase promoting complex/cyclosome (APC/C), a cell cycle-regulated E3 ubiquitin ligase that controls progression through mitosis and the G1 phase of the cell cycle. Interestingly, the partners of $A N A P C 2, C D C 20$ and $C D H 1$, were also upregulated in this tumor (Additional file 2: Figure S6), and $\mathrm{APC} / \mathrm{C}$ has a recently-documented important role in cancer, and can be inhibited with a small molecule (Tosyl-L-Arginine Methyl Ester). Another oncogenic ubiquitin ligase, UBE3A (aka E6-AP; marks TP53 for proteolysis degradation) was placed under control of the AR via fusion to the first exon of androgen responsive gene SLC45A3 in T11, although $U B E 3 A$ was not expressed at an outlier level in this tumor at the time of prostatectomy. Tumor T11 had an intact TP53 gene, but examination of copy number and mutation data (Additional file 2: Figure S6 and Additional file 3: Text S1) revealed that TP53 was disrupted in over half of the high-risk cohort (Additional file 2: Figure S7).

\section{A recurrent tandem duplication genotype in prostate cancer}

The two tumors expressing the greatest number of fusion genes were ETS negative (tumor T4 and LTL311; also $S P O P$ wild type), consistent with Baca et al.'s work demonstrating a higher frequency of genome rearrangement in this tumor subtype compared to ETS positive tumors [6]. Remarkably, in the hormone-naïve tumor T4 all 25 expressed fusion genes were intra-chromosomal, and were predicted to have arisen through individual tandem duplication events. The copy number profile of $\mathrm{T} 4$ was uncharacteristic of prostate cancer, replete with hundreds of focal gains (Figure 4A). Overlapping focal copy gains with genome rearrangement predictions revealed an additional 216 tandem duplications spread across the entire genome of T4 (241 in total; validation rate 100\% (13/13)) (Figure 4B; Additional file 1: Table S11). Several tandem duplication events had potential to contribute to cancer in T4, most notably the non-ETS fusion gene PDS5A-KLB (described above), and a high focal genome amplification of the $M D M 2$ gene loci (Figure 4C). The latter was caused by serial tandem duplication events across a roughly $3 \mathrm{Mb}$ region of chromosome 12 (confirmed by $\mathrm{CISH}$ in Figure 4E and F). MDM2 is an oncogenic ubiquitin ligase whose action leads to the degradation of TP53 (similar to UBE3A). $M D M 2$ was expressed very highly at the mRNA level in T4, and may counteract the intact TP53 gene in this tumor (Figure 4D). This is particularly intriguing in the context of the $U B E 3 A$ fusion gene described above, as it conceivably represents a distinct mechanism of TP53 control in prostate tumors and suggests therapeutic strategies which relieve ubiquitin-mediated TP53 repression may have efficacy [31,32].

The prostate cancer copy number 'signature' of $8 \mathrm{p}$ loss and $8 \mathrm{q}$ gain was still present in tumor $\mathrm{T} 4$, but overlaid 


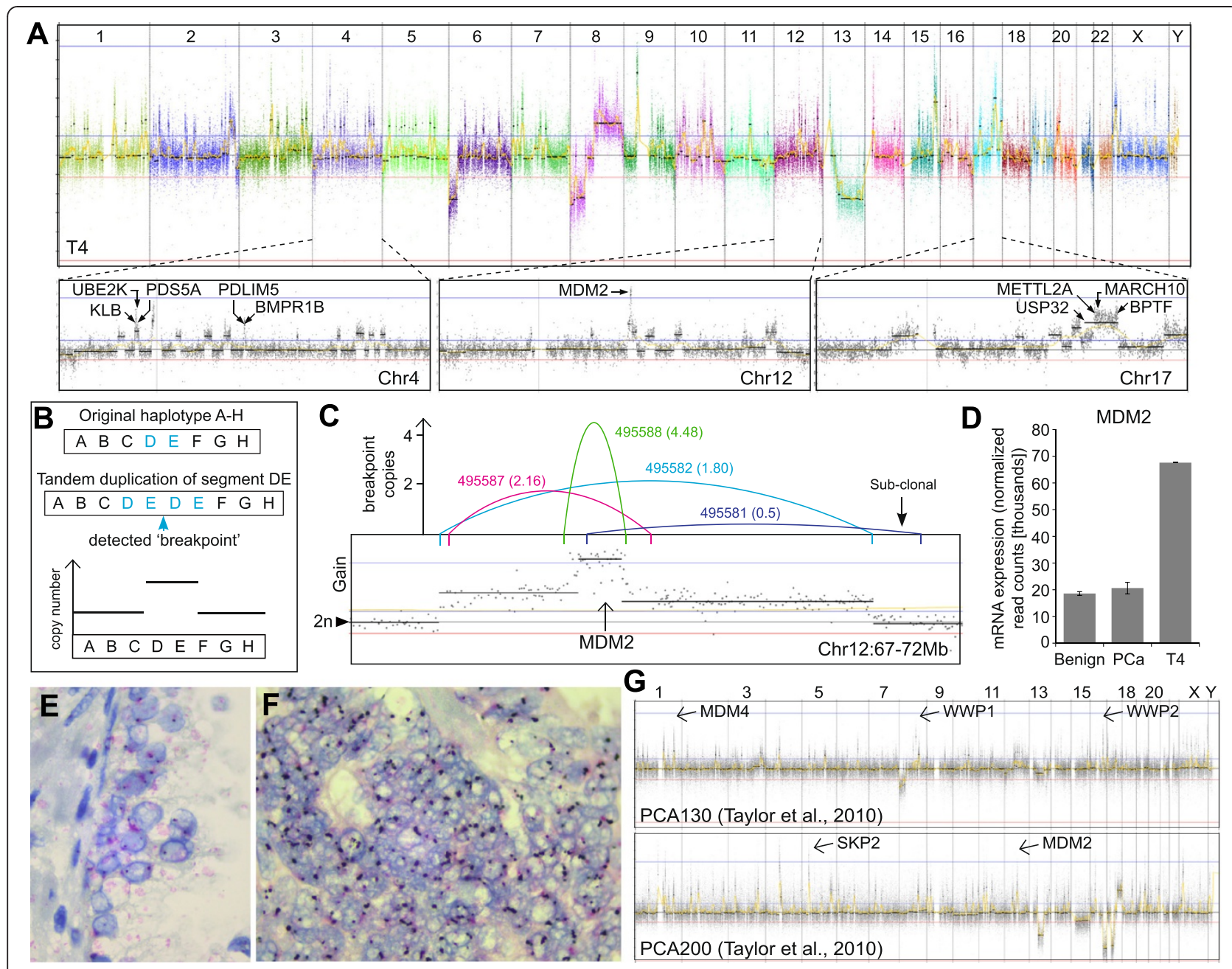

Figure 4 A tandem duplication genotype in high-risk prostate cancer. (A) Copy number profile of hormone-naïve tumor T4, showing focal gains across the entire genome, distinctive of tandem duplications. Key events discussed in the text are annotated. (B) Schematic illustrating how individual tandem duplications present at the genomic level. (C) Serial tandem duplications across the MDM2 loci in T4. The copy number plot shows a focal high gain, with the colored lines representing segments that have been duplicated. Tandem duplication ID is indicated next to each colored line and in brackets is the estimated number of copies of each tandem duplication. For example, the genetic breakpoint of the most focal tandem duplication (green line) was detectable at a high frequency indicating multiple copies, suggesting that the breakpoint itself had been subsequently duplicated, potentially by the broader tandem duplications (pink and blue lines). Note that one breakpoint (purple line) was predicted at $<1$ suggestive of sub-clonality and highlighting the potential for continual evolution. (D) Transcript expression of MDM2 across the high-risk cohort showing elevated expression in tumor T4 relative to the other tumors and benign samples. (E, F) Chromogenic in situ hybridization of MDM2 in benign tissue (E) and tumor (F) from T4 confirming MDM2 amplification. Note the 'clumps' of staining in the tumor cells suggesting MDM2 amplifications are proximally located (consistent with tandem duplication). (G) Copy number profiles from two tumors in a public dataset, which appear to harbor the distinctive pattern of focal gains across the entire genome (see Additional file 2: Figure S9 for further examples). Oncogenes within focal amplifications are annotated.

with tandem duplications. Furthermore the genome breakpoints of several tandem duplications were detectable only at sub-clonal levels (Figure 4C; Additional file 2: Figure S8) and had reduced copy number peaks relative to other gains. Together with the (serially-generated) amplification peaks of MDM2 and NRP2, these data suggest that the tandem duplication genotype arose over time rather than in a single catastrophic event (c.f. chromothripsis [33]), and that there may be a specific susceptibility to tandem duplication in T4.
Interestingly, the genotype of $\mathrm{T} 4$ appears highly similar to a recently reported 'tandem duplicator' genotype in ovarian and breast cancer [34,35], raising the possibility of a pan-cancer mechanism, and recurrence beyond this singleton case in prostate cancer. Therefore, we searched for evidence of similar cases in two external cohorts of copy number profiles from localized and metastatic prostate tumors $[5,8]$. Although categorical detection of tandem duplications is not possible from copy number data alone, we identified five tumor profiles with tens to 
hundreds of focal copy gains highly reminisce of tumor T4 (Figure 4G; Additional file 2: Figure S9). Furthermore, it is of note that the five prostate tumors putatively identified with the tandem duplication genotype were ETS rearrangement negative, $C H D 1$ wild-type, and where genotyping was carried out, SPOP wild-type (tumor T4 was also CHD1 and SPOP wild-type). As such it is probable that the tandem duplicator genotype is recurrent at low frequency in prostate tumors and may in fact comprise a distinct molecular class.

\section{Discussion}

We have characterized the transcriptomic landscape of 25 high-risk prostate tumors. Focus on non-recurrent aberration revealed considerable inter-tumor heterogeneity, and a diverse range of novel potentially-driving fusion genes and outlier transcript expression signatures, some of which may be therapeutically exploitable. Non-recurrent events still converged on distinct cancer-related functions and pathways, a finding assuming increased significance given the advent of precision medicine and a renewed motivation for accurate patient stratification.

We identified a tandem duplication genotype in the ETS-negative tumor T4 that appears to be recurrent at a low level in prostate, breast, and ovarian cancers. In T4, tandem duplications resulted in several potentially driving events via oncogene amplification (for example, $M D M 2$, NRP2), gene fusion (for example, PDS5A-KLB), or tumor suppressor disruption (for example, EP300). Inhibitors for MDM2 (and to a lesser extent NRP2) are in pre-clinical development [36,37], but the presence of multiple tandem duplications at sub-clonal proportions in $\mathrm{T} 4$ indicates a propensity for evolution in response to targeted therapy. The suggestion that tandem duplications are arising over multiple cell cycles helps distinguish the genotype from chromothripsis and chromoplexy, which are thought to occur in a single event, and are typically associated at the copy number level with multiple deletions (rather than focal gains) [6,33]. Evidence of recurrence of the tandem duplication genotype at low frequency in other prostate tumors, as well as in recent studies of breast and ovarian tumors $[34,35]$ suggests the possibility of a common cause, probably in defective DNA maintenance [38]. Interestingly, prostate tumors with evidence of the tandem duplication genotype were all ETS and CHD1 wild type, hinting at a distinct and novel molecular subtype. This hypothesis requires rapid confirmation in additional tumors, since the evident aggression of the genotype demands an early detection strategy.

Several high-risk tumors expressed unique, but potentially functional, non-ETS fusions. Non-ETS fusion transcripts have been previously identified in prostate tumors [39-41], but have been understudied due to their non-recurrence, and the predicted loss-of-function of the vast majority. Their clinical relevance requires further elucidation, and much will be revealed through transcriptome sequencing of advanced prostate tumors underway as part of the SU2C Dream Team efforts. However, it is interesting to speculate that the lack of androgen responsive promoters for the majority of potentially functional non-ETS rearrangements identified here may confer a benefit when under the stress of androgen blockade. Although the lower depth of our DNA sequencing precluded precise clonality estimates, several of the potentially functional fusions had read counts suggestive of sub-clonality, and it will be interesting to monitor whether they will be preferentially selected or lost over the course of disease. It may ultimately become possible to therapeutically exploit unique fusions such as those identified here, but in the near future non-ETS fusions have potential to complement patient stratification for precision medicine (for example, fusion of a PI3K subunit could imply stronger rationale for pathway inhibition). In parallel to the patient sequence cohort, we identified several potentially functional fusion genes in the ETS-negative PDX LTL311. This xenograft tumor was derived from a needle biopsy specimen obtained at diagnosis [13], and given the protracted disease course of prostate cancer it is therefore conceivable that target discovery and in vivo testing of personalized therapies is possible very early in disease course, at least for the highest risk cases.

The inability to determine whether a given aberration has historical or contemporary significance is a major drawback of genome-centric studies. However, as appropriate patient selection rapidly becomes a necessity for clinical trial design, it is imperative that we understand contemporary dependence on oncogenic or druggable pathways. Studies of outlier gene expression can give insight into contemporary drivers, and has considerable precedence in prostate cancer (for example, discovery of ETS fusions and SPINK1 subtype [42]), but the high dynamic range and absolute quantification afforded by transcriptome sequencing offers new opportunities not available to previous microarray-based approaches. In our study, we revealed highly statistically significant enrichment of outlier gene expression within distinct cellular pathways associated with metabolism, translation, cell cycle, and the immune system. These associations may reflect differing pathway reliance of individual tumors and therefore a rationale for discrete therapeutic strategies (for example, mTOR inhibition), although further functional studies are clearly required. Interestingly, where comparisons to matched benign tissue were possible, outlier gene pathway enrichment appeared to be specific to the tumor foci, even the immune-related pathways where one might assume lymphocyte infiltration to be prostate-wide. Some outlier gene signatures, such as 
the coordinated upregulation of glycolysis enzymes or the expression of specific chemokines, were detected in just a single tumor, highlighting both the remarkable diversity of gene usage, and the requirement for further characterization of individual tumor transcriptomes.

The logistical challenge of obtaining longitudinal tumor samples in patients with prostate cancer has long hampered research into therapy resistance. Although the application of 'liquid biopsies' to late-stage patients will undoubtedly reveal novel mechanisms of resistance, the study of neo-adjuvant treated primary tumors has proven to be a partial solution, leading for example to the discovery of the adaptive stress-response as an effective drug target [43]. Our study revealed a marked therapy effect in the 10 NHT tumors, and evidence of early drug resistance in one tumor (T20) via probable transdifferentiation of adenocarcinoma to neuroendocrine prostate cancer (NEPC). We recently reported a patient-derived xenograft model of primary adenocarcinoma which upon androgen ablation rapidly 'transdifferentiates' to complete NEPC via an adaptive response [13]. It seems likely that this is the situation in tumor T20, and underscores the urgent need to develop better biomarkers to monitor for early resistance.

\section{Conclusions}

Through the first deep transcriptome sequencing study of prostate tumors we have revealed surprising levels of inter-tumor heterogeneity converging on key functions and pathways, and conferring significant implications for precision medicine. Our study emphasizes the value of focusing on the individual rather than the cohort, especially when profiling extreme phenotypes, since we identified a diverse range of novel potentially-driving fusion genes, outlier transcript expression signatures and an aggressive tandem duplicator genotype.

\section{Methods}

\section{Sample collection and sequencing}

Prostate tissue was collected from high-risk patients undergoing radical prostatectomy and snap frozen according to the current Vancouver General Hospital pathology protocol. All patients signed a formal consent form approved by the ethics board, and in accordance with the Helsinki Declaration. High-risk cases were selected for this study by meeting any of the following criteria: Gleason $\geq 8$, PSA $\geq 20$, or clinical stage T3a and above. Hematoxylin and eosin (H\&E) stained FFPE and frozen sections were reviewed by an expert pathologist (LF) to identify blocks with highest tumor content. For each frozen block used, a $5 \mu \mathrm{m}$ slide was first taken for $\mathrm{H} \& \mathrm{E}$ staining, then $4 \times 100 \mu \mathrm{m}$ sections were taken for DNA and RNA isolation, before a second $5 \mu \mathrm{m}$ slide was taken for $H \& E$ staining. Each H\&E slide was required to have tumor content $>50 \%$ in order for a tumor to proceed for sequencing. Additionally, we included the patient-derived xenograft LTL311 in our sequencing cohort. LTL311 is derived from a needle biopsy of high-risk primary adenocarcinoma [13]. This tumor was included in the study to evaluate the suitability of modelling high-risk disease from biopsy tissue prior to prostatectomy.

For DNA isolation, digestion of $100 \mu \mathrm{m}$ snap-frozen tumour tissue with $0.2 \mathrm{mg} / \mathrm{mL}$ Proteinase $\mathrm{K}$ (Roche) in digestion buffer (50 mM NaCl, $10 \mathrm{mM}$ Tris- $\mathrm{HCl}$ (pH 8.3), $1 \mathrm{mM}$ EDTA and $0.5 \%$ SDS) was carried out overnight at $55^{\circ} \mathrm{C}$. Samples were incubated with RNase solution at $37^{\circ} \mathrm{C}$ for $30 \mathrm{~min}$ and treated with protein precipitation solution followed by isopropanol precipitation of the DNA. The DNA was further purified by Phenol:Chloroform:Isoamyl Alcohol (25:24:1), and precipitated by adding $1 / 10$ th volume of $3 \mathrm{M}$ sodium acetate and 2.5 volumes of $100 \%$ ethanol, before re-suspension in TE. RNA from snap-frozen tissue was isolated using the mirVana Isolation Kit from Ambion (AM 1560). DNA and RNA sequencing was performed on Illumina HiSeq 2000 at BCCA Michael Smith Genome Sciences Centre according to standard protocols. Four high-risk tumors sequenced on GAII in a previous study $[44,45]$ were re-sequenced on HiSeq 2000 for this study.

\section{Array comparative genomic hybridization copy number profiling}

A total of $0.5 \mu \mathrm{g}$ of each genomic DNA was fluorescently labeled by following the NimbleGen enzymatic labeling protocol which employs $\mathrm{Cy} 3$ and $\mathrm{Cy} 5$ labeled random nanomers (TriLink Biotechnologies), a heat fragmentation step at $98^{\circ} \mathrm{C}$ for $10 \mathrm{~min}$, and amplification with Klenow fragment 5'-3'exo- (New England Biolabs). Five micrograms of each Cy5-labeled sample was co-hybridized with $5 \mu \mathrm{g}$ of Cy3-labeled human male reference DNA (Promega Corp) on Agilent SurePrint G3 Human Catalog $\mathrm{CGH} 8 \times 60 \mathrm{~K}$ or $4 \times 180 \mathrm{k}$ slides following the Agilent Oligonucleotide Array-Based CGH for Genomic DNA Analysis Protocol v6.2. Arrays were scanned with the Agilent DNA Microarray Scanner, and quantified with Feature Extraction 10.5.1.1. CGH processed signal was uploaded into Biodiscovery Nexus CGH software v7, where quality was assessed and data were visualized and analyzed. Data is available at GEO accession number GSE55016.

\section{Sequence data mapping and processing}

Raw sequence data are available at The European Nucleotide Archive (ENA), accession number PRJEB6530. DNAseq reads were aligned onto the human reference genome (hg19/GRCh37) using BWA (0.5.9-r16) [46] allowing $1 \mathrm{nt}$ mismatch at most in a 24 nt seed. For RNA-seq, reads were mapped onto the hg19 genome and exon-exon 
junctions by splice-aware aligner Tophat [47], using the known gene model annotation from Ensembl release 62. Reads with an unmapped mate or multi-mapped location were filtered out using Bamtools [48] and PCR or sequencing optical duplicates were marked and removed by Picard [49]. Using NCBI dbSNP build 132, multiple sequence local realignment around InDels and base quality recalibration was performed by GATK (The Genome Analysis Toolkit) [50] to correct likely misalignments. For DNA and RNA sequencing data of all specimens, SNVs/InDels were identified and filtered by GATK [51] to achieve high-confidence sites (strand bias, base quality, mapping quality, and position bias were taken into account). Additionally for RNA-seq data, we used samtools [52] to call SNVs/InDels, and retained as high-confidence only those sites which were concordant between both GATK and samtools results. All variants were annotated with genic regions and potential consequences on proteincoding sequences using the tool AnnoVar [53]. The effect of non-synonymous SNVs on protein function was assessed using Condel [54], a method which integrates several predictive tools (for example, SIFT, Polyphen2, MutationAssessor). To prioritize variants we first filtered against dbSNP build 137 (non-flagged only) and the five adjacent benign samples sequenced in this study, and then only considered variants detectable in both DNA and RNA reads (that is, expressed variants). Finally we excluded identical variants concurrently predicted in more than two samples as likely artefact. Mutated genes present in either Cosmic Cancer Gene Consensus [55] or reported to be a 'Mut-Driver Gene' [56] are shown in Additional file 2: Figure S10 and Additional file 1: Table S12. Mutation frequency was calculated based on DNA-seq reads alone. Reads of reference and variant were counted after local realignment and duplicate removal.

Based on the alignment of RNA-seq reads, gene expression profiles for each sample were calculated based on the gene annotation (Ensembl release 62). Only reads which were unique to one gene and exactly corresponded to gene structure were assigned to the corresponding genes. Raw read counts were normalized by $\mathrm{R}$ package DESeq [57], which was designed for gene expression analysis of RNA-seq data across all samples. Transcript expression profiles for all samples are provided in Additional file 1: Table S4. DESeq was also used to compare transcript expression between neo-adjuvant treated and hormone naïve tumors (after exclusion of the two tumors with NEPC components (tumors T16 and T20)), using a Benjamini-Hochberg corrected $P$ value. To detect outlier gene expression across the cohort we used the Generalized Extreme Studentized Deviate (ESD) test [58] with an upper bound of 15 (half of the cohort size). Additionally, in order to filter out background noise and minimize artifact detection, we calculated the average background noise for each sample based on the coverage of inter-genic and intronic regions (which should be largely absent from pure RNAsequence data). After subtracting background noise, we required that an upregulated outlier gene have a sequence depth greater than 10X, while for a downregulated outlier gene, the average sequence depth of non-outliers must also be greater than 10X. Pathway and functional enrichment analyses of outlier genes was performed using the Ingenuity Knowledge Base (Ingenuity Systems [59]).

\section{Identification of fusion genes and genome rearrangements}

We used the deFuse algorithm [25] to predict rearrangements in RNA sequence libraries. Since there were approximately 8,000 unfiltered defuse predictions of chimeric RNAs after analyses of the 31 RNA sequence libraries (Additional file 4: Table S13), we filtered predictions according to the following criteria: a fusion gene candidate: (1) must be predicted to have arisen from genome rearrangement, rather than via a readthrough event; (2) must be predicted in no more than two sequence libraries (with the exception of ETS fusions; this step removes recurrent artifacts); (3) must map unambiguously on both sides of the predicted breakpoints (that is, no multi-mapping reads); (4) must not map entirely to repetitive elements; (5) must be detected in $>5$ reads (either split or spanning). This step reduced predicted fusion genes to $<1,000$, and candidates were then further prioritized by fulfilling any of the following secondary criteria: mapping to edge of copy number aberration, differential exon expression either side of breakpoints; outlier expression of 3' gene in that sample relative to others. Although this stringent filtering strategy has potential to remove some true positives, we felt that preferable to an elevated false discovery rate. To identify complex genome rearrangements underlying predicted fusion RNAs we applied the nFuse pipeline [60] to RNA and DNA sequence libraries. Validation was performed by PCR across the predicted fusion junctions in cDNA or gDNA (oligonucleotide sequences provided in Additional file 1: Table S9 and S10). All amplification products were sequenced with an ABI PRISM 310 Genetic Analyzer to confirm identity.

\section{Immunohistochemistry}

Immunohistochemical staining was conducted on serial sections ( $5 \mu \mathrm{m}$ thick) by Ventana autostainer model Discover XT TM (Ventana Medical System) with enzyme labeled biotin streptavidin system and solvent resistant DAB Map kit by using 1/50 of CHGA rabbit monoclonal antibody \# AC-0037 (Epitomics, Inc.), 1/200 concentration of AR (N-20) antibody \# SC-816 (Santa Cruz Biotechnology), and 1/500 of anti-Ki-67 rabbit monoclonal antibody clone SP6 (Thermo Scientific ${ }^{\text {Tm }}$ Lab Vision). For dual staining a Blue Map kit was used with 1/500 of CHGA mouse 
monoclonal antibody cat\# MAB5268 (Chemicon) and 1/50 concentration of AR (N-20) antibody cat \# SC-816 (Santa Cruz Biotechnology). For negative controls the primary antibodies were replaced with the corresponding species normal immunoglobulin G. Previously tested tissue samples from our tumor bank were used as positive controls.

Chromogenic in situ hybridization (CISH) was carried out using the Ventana discovery ultra-automated slide stainer two color method. After standard pre-treatment of formalin-fixed, paraffin-embedded human prostate cancer specimen, the tissues were subjected to protease digestion for $8 \mathrm{~min}$, followed by incubation with an MDM2 DNP labelled DNA probe and a Chromosome 12 DIG labelled DNA probe for $6 \mathrm{~h}$. Detection was carried out with Ventana's ultraView SISH DNP Detection Kit and Red ISH DIG Detection Kit. Finally the slides were counterstained with Hematoxylin II and blueing reagent. Fluorescence in situ hybridization (FISH) for ERG gene rearrangement was carried out using a previously documented protocol [61] and scored manually by an expert pathologist (RM).

\section{Additional files}

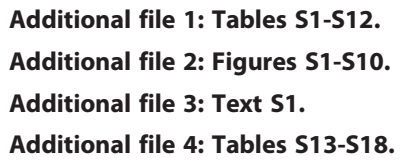

\section{Competing interests}

The University of Michigan has been issued a patent on the detection of ETS gene fusions in prostate cancer, on which RM and AMC are listed as co-inventors. The University of Michigan has licensed the diagnostic field of use to Gen-Probe, Inc. (Bedford, MA, USA), which has sublicensed some rights to Ventana Medical Systems. AMC has served as a consultant for Gen-Probe, Inc. and Ventana Medical Systems. RM serves as a consultant to GenomeDx Biosciences (Vancouver, BC, Canada).

\section{Authors' contributions}

AWW, FM, MEG, SV, and CCC designed the study. MEG, LF, SB, AHC, and JL were involved in surgical collection and processing of clinical specimens for sequencing. DL and $\mathrm{YW}$ provided xenograft tissue. FM performed sequence data mapping and processing. AWW, FM, KW, RLJ, JY, RShr, AL, and JB performed gene expression and outlier analysis. AWW, SV, DMM, and AM were involved in fusion gene and genomic rearrangement detection. $\mathrm{AH}$, $\mathrm{RHB}$, and SA carried out microarray experiments. Immunohistochemistry was carried out by $F L, E L$, and JL. RM, HX, and AMC performed fluorescence in situ hybridization experiments. BM, SB, RShu, LJ, and DM performed PCR validations. AWW, FM, and CCC wrote the paper. All authors read and approved the final manuscript.

\section{Acknowledgements}

This project was funded by: Prostate Cancer Canada (MEG, CCC), Prostate Cancer Foundation (JB, AMC, RM, YW, MEG, CCC), The Canadian Prostate Cancer Genome Network (CCC), Terry Fox Research Institute (CCC), Canadian Institutes of Health Research (YW). AWW is supported by a Coalition to Cure Prostate Cancer Young Investigator Award.

\section{Author details}

${ }^{1}$ Vancouver Prostate Centre \& Department of Urologic Sciences, University of British Columbia, 2660 Oak Street, Vancouver, BC V6H 3Z6, Canada.

${ }^{2}$ Bioinformatics Training Program, University of British Columbia, Vancouver, BC, Canada. ${ }^{3}$ Michigan Center for Translational Pathology, Ann Arbor, Michigan, USA. ${ }^{4}$ Department of Experimental Therapeutics, BC Cancer Agency, Vancouver, BC, Canada.

Received: 9 April 2014 Accepted: 28 July 2014

Published online: 26 August 2014

\section{References}

1. Wyatt AW, Mo F, Wang Y, Collins CC: The diverse heterogeneity of molecular alterations in prostate cancer identified through next-generation sequencing. Asian J Androl 2013, 15:301-308.

2. Spans L, Clinckemalie L, Helsen C, Vanderschueren D, Boonen S, Lerut E, Joniau S, Claessens F: The genomic landscape of prostate cancer. Int J Mol Sci 2013, 14:10822-10851.

3. Tomlins SA, Laxman B, Dhanasekaran SM, Helgeson BE, Cao X, Morris DS, Menon A, Jing X, Cao Q, Han B, Yu J, Wang L, Montie JE, Rubin MA, Pienta KJ, Roulston D, Shah RB, Varambally S, Mehra R, Chinnaiyan AM: Distinct classes of chromosomal rearrangements create oncogenic ETS gene fusions in prostate cancer. Nature 2007, 448:595-599.

4. Barbieri CE, Baca SC, Lawrence MS, Demichelis F, Blattner M, Theurillat JP, White TA, Stojanov P, Van Allen E, Stransky N, Nickerson E, Chae SS, Boysen G, Auclair D, Onofrio RC, Park K, Kitabayashi N, MacDonald TY, Sheikh K, Vuong T, Guiducci C, Cibulskis K, Sivachenko A, Carter SL, Saksena G, Voet D, Hussain WM, Ramos AH, Winckler W, Redman MC, et al: Exome sequencing identifies recurrent SPOP, FOXA1 and MED12 mutations in prostate cancer. Nat Genet 2012, 44:685-689.

5. Grasso CS, Wu YM, Robinson DR, Cao X, Dhanasekaran SM, Khan AP, Quist MJ, Jing X, Lonigro RJ, Brenner JC, Asangani IA, Ateeq B, Chun SY, Siddiqui J, Sam L, Anstett M, Mehra R, Prensner JR, Palanisamy N, Ryslik GA, Vandin F, Raphael BJ, Kunju LP, Rhodes DR, Pienta KJ, Chinnaiyan AM, Tomlins SA: The mutational landscape of lethal castration-resistant prostate cancer. Nature 2012, 487:239-243.

6. Baca SC, Prandi D, Lawrence MS, Mosquera JM, Romanel A, Drier Y, Park K, Kitabayashi N, MacDonald TY, Ghandi M, Van Allen E, Kryukov GV, Sboner A, Theurillat JP, Soong TD, Nickerson E, Auclair D, Tewari A, Beltran H, Onofrio RC, Boysen G, Guiducci C, Barbieri CE, Cibulskis K, Sivachenko A, Carter SL, Saksena G, Voet D, Ramos AH, Winckler W, et al: Punctuated evolution of prostate cancer genomes. Cell 2013, 153:666-677.

7. Meng MV, Elkin EP, Latini DM, Duchane J, Carroll PR: Treatment of patients with high risk localized prostate cancer: results from cancer of the prostate strategic urological research endeavor (CaPSURE). J Urol 2005, 173:1557-1561.

8. Taylor BS, Schultz N, Hieronymus H, Gopalan A, Xiao Y, Carver BS, Arora VK, Kaushik P, Cerami E, Reva B, Antipin Y, Mitsiades N, Landers T, Dolgalev I, Major JE, Wilson M, Socci ND, Lash AE, Heguy A, Eastham JA, Scher HI, Reuter VE, Scardino PT, Sander C, Sawyers CL, Gerald WL: Integrative genomic profiling of human prostate cancer. Cancer Cell 2010, 18:11-22.

9. Attard G, Cooper CS, de Bono JS: Steroid hormone receptors in prostate cancer: a hard habit to break? Cancer Cell 2009, 16:458-462.

10. Sorrentino C, Musiani P, Pompa P, Cipollone G, Di Carlo E: Androgen deprivation boosts prostatic infiltration of cytotoxic and regulatory $\mathrm{T}$ lymphocytes and has no effect on disease-free survival in prostate cancer patients. Clin Cancer Res 2011, 17:1571-1581.

11. Tang S, Moore ML, Grayson JM, Dubey P: Increased CD8+ T-cell function following castration and immunization is countered by parallel expansion of regulatory T cells. Cancer Res 2012, 72:1975-1985.

12. Beltran H, Tagawa ST, Park K, MacDonald T, Milowsky MI, Mosquera JM, Rubin MA, Nanus DM: Challenges in recognizing treatment-related neuroendocrine prostate cancer. J Clin Oncol 2012, 30:e386-e389.

13. Lin D, Wyatt AW, Xue H, Wang Y, Dong X, Haegert A, Wu R, Brahmbhatt S, Mo F, Jong L, Bell RH, Anderson S, Hurtado-Cull A, Fazli L, Sharma M, Beltran H, Rubin MA, Cox ME, Gout PW, Morris J, Goldenberg L, Volik SV, Gleave ME, Collins CC: High fidelity patient-derived xenografts for accelerating prostate cancer discovery and drug development. Cancer Res 2014, 74:1272-1283

14. Williamson SR, Zhang S, Yao JL, Huang J, Lopez-Beltran A, Shen S, Osunkoya AO, MacLennan GT, Montironi R, Cheng L: ERG-TMPRSS2 rearrangement is 
shared by concurrent prostatic adenocarcinoma and prostatic small cell carcinoma and absent in small cell carcinoma of the urinary bladder: evidence supporting monoclonal origin. Mod Pathol 2011, 24:1120-1127.

15. Lotan TL, Gupta NS, Wang W, Toubaji A, Haffner MC, Chaux A, Hicks JL, Meeker AK, Bieberich CJ, De Marzo AM, Epstein Jl, Netto GJ: ERG gene rearrangements are common in prostatic small cell carcinomas. Mod Pathol 2011, 24:820-828.

16. Guo CC, Dancer JY, Wang Y, Aparicio A, Navone NM, Troncoso P, Czerniak BA: TMPRSS2-ERG gene fusion in small cell carcinoma of the prostate. Hum Pathol 2011, 42:11-17.

17. Beltran H, Rickman DS, Park K, Chae SS, Sboner A, MacDonald TY, Wang Y, Sheikh KL, Terry S, Tagawa ST, Dhir R, Nelson JB, de la Taille A, Allory Y, Gerstein MB, Perner S, Pienta KJ, Chinnaiyan AM, Wang Y, Collins CC, Gleave ME, Demichelis F, Nanus DM, Rubin MA: Molecular characterization of neuroendocrine prostate cancer and identification of new drug targets. Cancer Discovery 2011, 1:487-495.

18. Wissing MD, Mendonca J, Kortenhorst MS, Kaelber NS, Gonzalez M, Kim E, Hammers H, van Diest PJ, Carducci MA, Kachhap SK: Targeting prostate cancer cell lines with polo-like kinase 1 inhibitors as a single agent and in combination with histone deacetylase inhibitors. FASEB J 2013, 27:4279-4293.

19. Chiu YT, Han HY, Leung SC, Yuen HF, Chau CW, Guo Z, Qiu Y, Chan KW, Wang $X$, Wong YC, Ling MT: CDC25A functions as a novel Ar corepressor in prostate cancer cells. J Mol Biol 2009, 385:446-456.

20. Chen S, Xu Y, Yuan X, Bubley GJ, Balk SP: Androgen receptor phosphorylation and stabilization in prostate cancer by cyclindependent kinase 1. Proc Natl Acad Sci U S A 2006, 103:15969-15974.

21. Hsieh AC, Liu Y, Edlind MP, Ingolia NT, Janes MR, Sher A, Shi EY, Stumpf CR, Christensen C, Bonham MJ, Wang S, Ren P, Martin M, Jessen K, Feldman ME, Weissman JS, Shokat KM, Rommel C, Ruggero D: The translational landscape of mTOR signalling steers cancer initiation and metastasis. Nature 2012, 485:55-61.

22. Ruggero D, Pandolfi PP: Does the ribosome translate cancer? Nat Rev Cancer 2003, 3:179-192.

23. Pelicano H, Xu RH, Du M, Feng L, Sasaki R, Carew JS, Hu Y, Ramdas L, Hu L, Keating MJ, Zhang W, Plunkett W, Huang P: Mitochondrial respiration defects in cancer cells cause activation of Akt survival pathway through a redox-mediated mechanism. J Cell Biol 2006, 175:913-923.

24. Rubin MA, Maher CA, Chinnaiyan AM: Common gene rearrangements in prostate cancer. J Clin Oncol 2011, 29:3659-3668.

25. McPherson A, Hormozdiari F, Zayed A, Giuliany R, Ha G, Sun MG, Griffith M, Heravi Moussavi A, Senz J, Melnyk N, Pacheco M, Marra MA, Hirst M, Nielsen TO, Sahinalp SC, Huntsman D, Shah SP: DeFuse: an algorithm for gene fusion discovery in tumor RNA-Seq data. PLoS Comput Biol 2011, 7:e1001138.

26. Krohn A, Seidel A, Burkhardt L, Bachmann F, Mader M, Grupp K, Eichenauer T, Becker A, Adam M, Graefen M, Huland H, Kurtz S, Steurer S, Tsourlakis MC, Minner S, Michl U, Schlomm T, Sauter G, Simon R, Sirma H: Recurrent deletion of 3 p13 targets multiple tumour suppressor genes and defines a distinct subgroup of aggressive ERG fusion-positive prostate cancers. J Pathol 2013, 231:130-141.

27. Osborne MJ, Volpon L, Kornblatt JA, Culjkovic-Kraljacic B, Baguet A, Borden $\mathrm{KL}$ : elF4E3 acts as a tumor suppressor by utilizing an atypical mode of methyl-7-guanosine cap recognition. Proc Natl Acad Sci U S A 2013, 110:3877-3882.

28. Feng S, Dakhova O, Creighton CJ, Ittmann M: Endocrine fibroblast growth factor FGF19 promotes prostate cancer progression. Cancer Res 2013, 73:2551-2562.

29. Bookout AL, de Groot MH, Owen BM, Lee S, Gautron L, Lawrence HL, Ding X, Elmquist JK, Takahashi JS, Mangelsdorf DJ, Kliewer SA: FGF21 regulates metabolism and circadian behavior by acting on the nervous system. Nat Med 2013, 19:1147-1152

30. Darby S, Cross SS, Brown NJ, Hamdy FC, Robson CN: BMP-6 over-expression in prostate cancer is associated with increased Id-1 protein and a more invasive phenotype. J Pathol 2008, 214:394-404.

31. Nakayama Kl, Nakayama K: Ubiquitin ligases: cell-cycle control and cancer. Nat Rev Cancer 2006, 6:369-381.

32. Sun Y: E3 ubiquitin ligases as cancer targets and biomarkers. Neoplasia 2006, 8:645-654

33. Stephens PJ, Greenman CD, Fu B, Yang F, Bignell GR, Mudie LJ, Pleasance ED, Lau KW, Beare D, Stebbings LA, McLaren S, Lin ML, McBride DJ, Varela I,
Nik-Zainal S, Leroy C, Jia M, Menzies A, Butler AP, Teague JW, Quail MA, Burton J, Swerdlow H, Carter NP, Morsberger LA, lacobuzio-Donahue C, Follows GA, Green AR, Flanagan AM, Stratton MR, et al: Massive genomic rearrangement acquired in a single catastrophic event during cancer development. Cell 2011, 144:27-40

34. McBride DJ, Etemadmoghadam D, Cooke SL, Alsop K, George J, Butler A Cho J, Galappaththige D, Greenman C, Howarth KD, Lau KW, Ng CK, Raine K, Teague J, Wedge DC, Cancer Study Group AO, Caubit X, Stratton MR, Brenton JD, Campbell PJ, Futreal PA, Bowtell DD: Tandem duplication of chromosomal segments is common in ovarian and breast cancer genomes. J Pathol 2012, 227:446-455.

35. Ng CK, Cooke SL, Howe K, Newman S, Xian J, Temple J, Batty EM, Pole JC, Langdon SP, Edwards PA, Brenton JD: The role of tandem duplicator phenotype in tumour evolution in high-grade serous ovarian cancer. J Pathol 2012, 226:703-712.

36. Goel HL, Chang C, Pursell B, Leav I, Lyle S, Xi HS, Hsieh CC, Adisetiyo H, Roy-Burman P, Coleman IM, Nelson PS, Vessella RL, Davis RJ, Plymate SR, Mercurio AM: VEGF/neuropilin-2 regulation of Bmi-1 and consequent repression of IGF-IR define a novel mechanism of aggressive prostate cancer. Cancer Discovery 2012, 2:906-921.

37. Wade M, Li YC, Wahl GM: MDM2, MDMX and p53 in oncogenesis and cancer therapy. Nat Rev Cancer 2013, 13:83-96.

38. Stephens PJ, McBride DJ, Lin ML, Varela I, Pleasance ED, Simpson JT, Stebbings LA, Leroy C, Edkins S, Mudie L, Greenman CD, Jia M, Latimer C, Teague JW, Lau KW, Burton J, Quail MA, Swerdlow H, Churcher C, Natrajan R, Sieuwerts AM, Martens JW, Silver DP, Langerod A, Russnes HE, Foekens $J A$, Reis-Filho JS, Vant Veer L, Richardson AL, Borresen-Dale AL, et al: Complex landscapes of somatic rearrangement in human breast cancer genomes. Nature 2009, 462:1005-1010.

39. Pflueger D, Terry S, Sboner A, Habegger L, Esgueva R, Lin PC, Svensson MA, Kitabayashi N, Moss BJ, MacDonald TY, Cao X, Barrette T, Tewari AK, Chee MS, Chinnaiyan AM, Rickman DS, Demichelis F, Gerstein MB, Rubin MA: Discovery of non-ETS gene fusions in human prostate cancer using next-generation RNA sequencing. Genome Res 2011, 21:56-67.

40. Weischenfeldt J, Simon R, Feuerbach L, Schlangen K, Weichenhan D, Minner S, Wuttig D, Warnatz HJ, Stehr H, Rausch T, Jager N, Gu L, Bogatyrova O, Stutz AM, Claus R, Eils J, Eils R, Gerhauser C, Huang PH, Hutter B, Kabbe R, Lawerenz C, Radomski S, Bartholomae CC, Falth M, Gade S, Schmidt M, Amschler N, Hass T, Galal R, et al: Integrative genomic analyses reveal an androgen-driven somatic alteration landscape in early-onset prostate cancer. Cancer Cell 2013, 23:159-170.

41. Palanisamy N, Ateeg B, Kalyana-Sundaram S, Pflueger D, Ramnarayanan K, Shankar S, Han B, Cao Q, Cao X, Suleman K, Kumar-Sinha C, Dhanasekaran SM, Chen YB, Esgueva R, Banerjee S, LaFargue CJ, Siddiqui J, Demichelis F, Moeller P, Bismar TA, Kuefer R, Fullen DR, Johnson TM, Greenson JK, Giordano TJ, Tan P, Tomlins SA, Varambally S, Rubin MA, Maher CA, et al: Rearrangements of the RAF kinase pathway in prostate cancer, gastric cancer and melanoma. Nat Med 2010, 16:793-798.

42. Tomlins SA, Rhodes DR, Yu J, Varambally S, Mehra R, Perner S, Demichelis F, Helgeson BE, Laxman B, Morris DS, Cao Q, Cao X, Andren O, Fall K, Johnson L, Wei JT, Shah RB, Al-Ahmadie H, Eastham JA, Eggener SE, Fine SW, Hotakainen K, Stenman UH, Tsodikov A, Gerald WL, Lilja H, Reuter VE, Kantoff PW, Scardino PT, Rubin MA, et al: The role of SPINK1 in ETS rearrangement-negative prostate cancers. Cancer Cell 2008, 13:519-528.

43. Matsumoto H, Yamamoto $Y$, Shiota M, Kuruma H, Beraldi E, Matsuyama H, Zoubeidi A, Gleave M: Cotargeting androgen receptor and clusterin delays castrate-resistant prostate cancer progression by inhibiting adaptive stress response and AR stability. Cancer Res 2013, 73:5206-5217.

44. Lapuk AV, Wu C, Wyatt AW, McPherson A, McConeghy BJ, Brahmbhatt S, Mo F, Zoubeidi A, Anderson S, Bell RH, Haegert A, Shukin R, Wang Y, Fazli L, Hurtado-Coll A, Jones EC, Hach F, Hormozdiari F, Hajiresouliha I, Boutros PC, Bristow RG, Zhao Y, Marra MA, Fanjul A, Maher CA, Chinnaiyan AM, Rubin MA, Beltran H, Sahinalp SC, Gleave ME, et al: From sequence to molecular pathology, and a mechanism driving the neuroendocrine phenotype in prostate cancer. J Pathol 2012, 227:286-297.

45. Wu C, Wyatt AW, Lapuk AV, McPherson A, McConeghy BJ, Bell RH, Anderson S, Haegert A, Brahmbhatt S, Shukin R, Mo F, Li E, Fazli L, Hurtado-Coll A, Jones EC, Butterfield YS, Hach F, Hormozdiari F, Hajirasouliha I, Boutros PC, Bristow RG, Jones SJ, Hirst M, Marra MA, Maher CA, Chinnaiyan AM, Sahinalp SC, Gleave ME, Volik SV, Collins CC: Integrated genome and transcriptome sequencing 
identifies a novel form of hybrid and aggressive prostate cancer. $J$ Pathol 2012, 227:53-61.

46. Li H, Durbin R: Fast and accurate long-read alignment with Burrows-Wheeler transform. Bioinformatics 2010, 26:589-595.

47. Trapnell C, Pachter L, Salzberg SL: TopHat: discovering splice junctions with RNA-Seq. Bioinformatics 2009, 25:1105-1111.

48. Barnett DW, Garrison EK, Quinlan AR, Strömberg MP, Marth GT: BamTools: a $\mathrm{C}++\mathrm{API}$ and toolkit for analyzing and managing BAM files. Bioinformatics 2011, 27:1691-1692.

49. Picard. [http://picard.sourceforge.net]

50. DePristo MA, Banks E, Poplin R, Garimella KV, Maguire JR, Hartl C, Philippakis AA, Del Angel G, Rivas MA, Hanna M: A framework for variation discovery and genotyping using next-generation DNA sequencing data. Nat Genet 2011, 43:491-498.

51. McKenna A, Hanna M, Banks E, Sivachenko A, Cibulskis K, Kernytsky A, Garimella K, Altshuler D, Gabriel S, Daly M: The Genome Analysis Toolkit: a MapReduce framework for analyzing next-generation DNA sequencing data. Genome Res 2010, 20:1297-1303.

52. Li H: Improving SNP discovery by base alignment quality. Bioinformatics 2011, 27:1157-1158

53. Wang $\mathrm{K}, \mathrm{Li} \mathrm{M}, \mathrm{Hakonarson} \mathrm{H}$ : ANNOVAR: functional annotation of genetic variants from high-throughput sequencing data. Nucleic Acids Res 2010, 38:e164.

54. González-Pérez A, López-Bigas N: Improving the assessment of the outcome of nonsynonymous SNVs with a consensus deleteriousness score, Condel. Am J Hum Genet 2011, 88:440-449.

55. Futreal PA, Coin L, Marshall M, Down T, Hubbard T, Wooster R, Rahman N, Stratton MR: A census of human cancer genes. Nat Rev Cancer 2004, 4:177-183.

56. Vogelstein B, Papadopoulos N, Velculescu VE, Zhou S, Diaz LA Jr, Kinzler KW: Cancer genome landscapes. Science 2013, 339:1546-1558.

57. Anders $S$, Huber W: Differential expression analysis for sequence count data. Genome Biol 2010, 11:R106.

58. Rosner B: Percentage points for a generalized Esd many-outlier procedure. Technometrics 1983, 25:165-172.

59. Ingenuity Pathway Analysis. [http://www.ingenuity.com]

60. McPherson A, Wu C, Wyatt AW, Shah S, Collins C, Sahinalp SC: nFuse: Discovery of complex genomic rearrangements in cancer using high-throughput sequencing. Genome Res 2012, 22:2250-2261.

61. Mehra R, Tomlins SA, Yu J, Cao X, Wang L, Menon A, Rubin MA, Pienta KJ, Shah RB, Chinnaiyan AM: Characterization of TMPRSS2-ETS gene aberrations in androgen-independent metastatic prostate cancer. Cancer Res 2008, 68:3584-3590.

doi:10.1186/s13059-014-0426-y

Cite this article as: Wyatt et al:: Heterogeneity in the inter-tumor

transcriptome of high risk prostate cancer. Genome Biology 2014 15:426.

\section{Submit your next manuscript to BioMed Central and take full advantage of:}

- Convenient online submission

- Thorough peer review

- No space constraints or color figure charges

- Immediate publication on acceptance

- Inclusion in PubMed, CAS, Scopus and Google Scholar

- Research which is freely available for redistribution 